\title{
Explaining factors affecting individual innovation: The case of producer group members in Thailand
}

\author{
Karun Pratoom • Gomon Savatsomboon
}

Published online: 31 December 2010

(C) The Author(s) 2010. This article is published with open access at Springerlink.com

\begin{abstract}
Individual innovation and its antecedent factors, both at the group and individual level, are becoming a topic of increasing interest to entrepreneurs. However, research on this area has not yet proved adequate. This study aims to develop and test a multilevel model of antecedents of group members' innovation. Constructive culture and knowledge management are treated as group-level antecedents. Creativity and self-leadership are treated as individual-level antecedents. Data are collected from 1,526 group members in 138 producer groups of community products in the Northeast of Thailand. Results indicate that creativity fully mediates the effects of self-leadership, groups' constructive culture, and knowledge management on innovation among group members. Furthermore, constructive culture also moderates the effects of creativity on innovation.
\end{abstract}

Keywords Individual innovation - Constructive culture $\cdot$ Knowledge management Self-leadership · Creativity · Thailand

In the age of globalization, individual innovation within the workplace is the foundation of high-performance (Carmeli, Meitar, \& Weisberg, 2006; Janssen, Van de Vliert, \& West, 2004). It has been considered as an important source of firm innovation that may improve firm's competitiveness (Schilling, 2008) and foster long-term success (Smith, 2002). However, innovation is a complex process due to the fact it does not arise from any one particular source, but rather, it involves a linkage between multiple sources (Schilling, 2008), both at the firm and the individual levels. Unfortunately, most existing research into innovation has focused at the firm level and few studies have directly tested the intermediate processes

\footnotetext{
K. Pratoom $(\bowtie) \cdot$ G. Savatsomboon

Faculty of Accountancy and Management, Mahasarakham University, Maha Sarakham, Thailand e-mail: karun_patoom@yahoo.com

G. Savatsomboon

e-mail: gamon.s@acc.msu.ac.th
} 
through which individual and contextual factors affect individual innovation (Oldham \& Cummings, 1996; Yuan, 2005). The lack of research in this area limits our understanding of exactly how and why individual differences and contextual factors are affecting individual innovation.

The practical innovation development among Thai firms and Thai innovators is an important mechanism for improving Thailand's level of competitiveness (Chutiwanichayakul, 2005). The community product project is one of the government's mega projects that aims at encouraging Thai rural entrepreneurs to use and improve their unique wisdom and resources, in order to create values and earn a living by themselves (Thanathikom, 2005). The Thai government has attempted to increase the quality of community products to a level that matches global standards and expand the market to an international level through innovation development activities (Tongboonrawd \& Sukpradit, 2007). However, the high rate of entrepreneurial activity does not adequately reflect the success of the community product business (Tongboonrawd \& Sukpradit, 2007). Less than 10\% of community products are high quality and exportable products (Thai Tambon, 2010). Hence, the purpose of this study is to develop and test a multilevel framework, in which group member innovation is examined as a joint function of group member characteristics and group environment characteristics.

Creativity is the most important individual-level factor affecting group member innovation (Cummings \& Oldham, 1997; Woodman, Sawyer, \& Griffin, 1993), especially for Thai community products (Thanathikom, 2005). Thai community products are the unique craft products that include the thinking processes, natural conservation, local wisdom, cultures, and traditions (Youngsuksathaporn, 2005). However, creativity alone is insufficient for developing an innovation (Anderson, De Dreu, \& Nijstad, 2004). The individual must have a certain level of internal force that pushes them to persevere in the face of challenges in creative work (Shalley \& Gilson, 2004). Previous case studies reveal that community product producers with a high level of self-leadership (i.e., ambition, self-determination) are more likely to be successful innovative entrepreneurs (Thanathikom, 2005). Carmeli et al. (2006) found that self-leadership skill is an individual-level factor that fosters individual innovation. Hence, in this study, we have combined creativity and self-leadership as the basic individual-level factors to explain group members' innovation.

As argued above, creativity and self-leadership positively influence individual innovation. However, only a few studies have examined the group-level conditions affecting individual innovation through creativity and self-leadership.

Previous works have suggested that firm knowledge management (Aulawi, Sudirman, Suryadi, \& Govindaraju, 2009; Muhammed, Doll, \& Deng, 2008) indirectly affects the individual innovation via creativity. In the Thai context, Tongboonrawd and Sukpradit's (2007) case study showed that local knowledge management positively affects innovation, which in turn contributes to the survivability of Thai community product producers. Local knowledge can be classified as institution-based knowledge because it is valid in Thailand but not valid in other countries (Peng, Wang, \& Jiang, 2008). According to Peng et al. (2008), institution-based knowledge is a key resource for building a differentiated competitive advantage in international business. In this study, knowledge management is selected as a group-level factor for predicting group member innovation. 
Several authors suggested that individual creativity (McLean, 2005; Parzefall, Seeck, \& Leppänen, 2008) and self-leadership (D'Intino, Golgsby, Houghton, \& Neck, 2007) can be enhanced in the constructive culture where risk taking is supported. On the other hand, the attitudes in a Thai cultural context are moderately high in uncertainty avoidance, thus, they are more likely to resort to strategies that will reduce risks (Pornpitakpan, 2000). In the organization context, the innovation of Thai employees may be impeded because of the culturally low acceptance of failure (Wongtada \& Rice, 2008). Therefore, group culture may be an important factor that supports or inhibits group member's innovation of Thai producer groups. Although the links among these variables have been theoretically suggested, empirical studies have not examined the moderating role of group culture while investigating the relationship between creativity, self-leadership, and individual innovation. Due to the characteristics and values of Thai culture being different from Western culturesbeing higher in uncertainty avoidance, having greater concern with security in life, having a greater trust in experts and their knowledge compared with Western countries (Pornpitakpan, 2000)_-group culture based on constructive dimension is selected as a contextual factor for explaining group member innovation.

Based on the argument above, Figure 1 depicts the theoretical framework of this study. The model is tested on a member of community product producer groups in Thailand. This study contributes to the existing literature in two ways. First, this study is among the first attempts to hypothesize and test the links between knowledge management and individual innovation based on the institution-based view and multilevel theory. Research in this area in the Asia Pacific is still in a developmental stage (Lu, Tsang, \& Peng, 2008). Second, within a Thai context, findings will help to clarify the process by which group and individual factors are affecting group member innovation, and will point out directions for improving the innovation development activities for Thai community product producer groups. In addition, this study differs from research in the developed countries in two ways: It

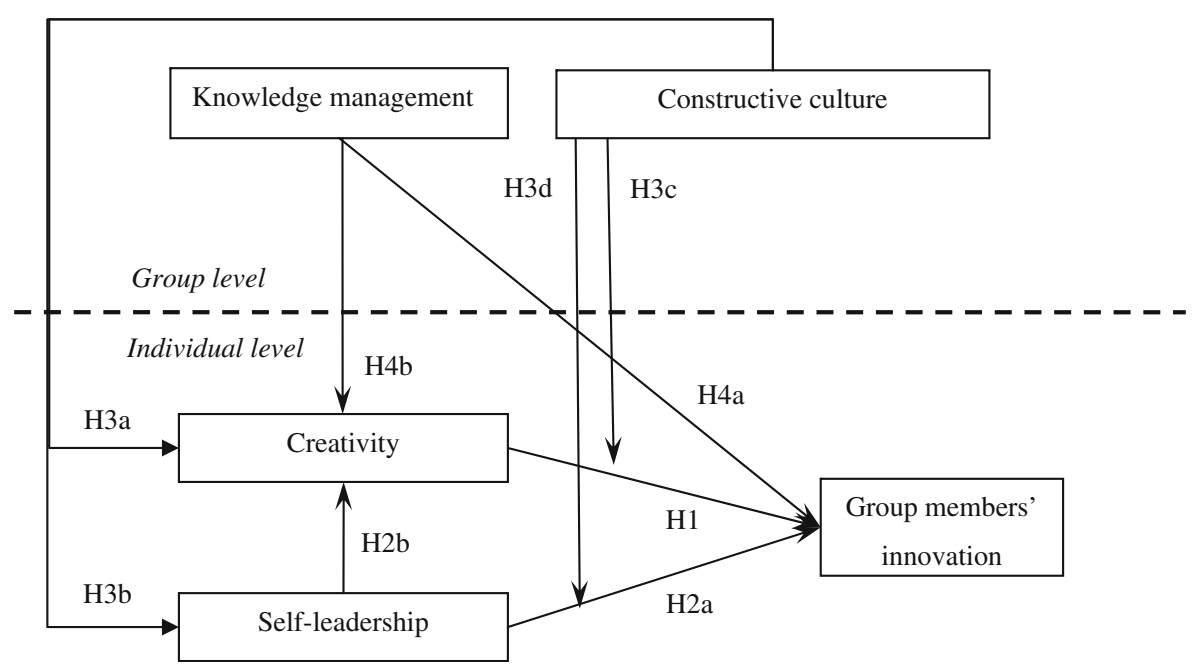

Figure 1 The hypothesized model 
investigates (1) an innovation at the individual level and its antecedent factors both at group and individual levels and in a Thai context; and (2) the nature of the relationship among these factors (mediation and moderation relationships).

\section{Theoretical background and hypotheses}

Definition of group and group members' innovation

In the business world, innovation is defined as new products, services, or work processes that help a firm gain a competitive advantage (Schilling, 2008). Creative theorists (e.g., Amabile, 1999; Amabile, Conti, Coon, Lazenby, \& Herron, 1996) defined innovation as the successful implementation of creative ideas within an organization. Based on this definition, we define group innovation as the new and useful products and procedures that the group successfully implements. Similarly, group members' innovation refers to the successful exploitation of new and useful ideas of the individual within a group. According to Cumming and Oldham (1997), when employees generate novel and useful products or procedures, they are essentially providing the firm with options. Employee innovations enable a firm to choose from a broader array of products or procedures for development and later implementation. This variety provides the firm with flexibility with which it can respond to external demands and opportunities. Thus, employee innovations can be the inputs for a firm to innovate. Based on this argument, if the group considers their members' innovation as incomplete implementation of creative ideas, members' innovation will be the inputs for further innovation of the group. On the other hand, if group members' innovation is considered as complete implementation, it may become an innovation of the group.

However, group and group members' innovation does not arise from any one source, but rather from linkages between multiple sources (Schilling, 2008). These sources of innovation can be divided into two: those at the individual level and those at the group level. At the individual level, several authors suggest that individual creativity (Heye, 2006; Schilling, 2008) and self-leadership (DiLiello \& Houghton, 2006) are important antecedents of innovation. Knowledge management (Aulawi et al., 2009; Muhammed et al., 2008) and culture (Janssen et al., 2004) are the antecedents at the group level. In addition, previous conceptual papers also suggest that organizational culture may substantially influence individual creativity and selfleadership (D'Intino et al., 2007; Manz \& Sims, 1989). In the next sections, we will present the links between these factors and the innovation of group members.

\section{Effects of creativity and self-leadership on innovation among group members}

While innovation is the successful implementation of novel ideas, creativity is defined as the ability to produce novel, potentially useful ideas about firms' products, practices, services, or procedures (Shalley \& Gilson, 2004). In this study, creativity refers to group members' ability to produce ideas that are useful and novel for their group. Given this definition, novelty is not considered an absolute term (novel versus not novel) but rather a continuum, with ideas possessing different 
degrees of novelty, from somewhat new and incremental to radically new and original (Madjar, 2005). Organizational creative theorists (e.g., Scott, 1995; West, 1990) have argued that individual's creativity is important in itself and can be conceptualized as a necessary first step or precondition required for innovation. A member with high ability to generate new and useful ideas is more likely to create their own innovation, which in turn contributes to group innovation (Woodman et al., 1993). Underlying this theoretical view, ability in generating new and useful ideas increases the likelihood of producing innovation. Hence, we expect creative group member to produce novel products or work processes. Therefore, we test the following hypothesis:

Hypothesis 1 Creativity positively affects group members' innovation.

Anderson et al. (2004) stated that creativity alone is insufficient for developing an innovation. Also, individuals must have a certain level of internal force that pushes them to persevere in the face of challenges in creative work (Shalley \& Gilson, 2004). A previous case study in Thailand has shown that community product producers with a high level of ambition, self-determination, ability to work under pressure, and at the same time be optimistic to respond positively to any challenge are more likely to be successful innovative entrepreneurs (Thanathikom, 2005). The characteristics expressed above are consistent with the self-leadership construct.

According to Pearce and Manz (2005), self-leadership is essential in those organizations that need continuous innovation. Self-leadership is defined as the process of influencing or leading oneself through the use of specific sets of behavioral and cognitive strategies (Manz \& Neck, 2004). Behavioral strategies include encouraging the positive, desirable behaviors that lead to successful outcomes, while suppressing the negative, undesirable behaviors that lead to an unsuccessful outcome (Neck \& Houghton, 2006). Cognitive strategies include creating feelings of selfdetermination and formation of constructive thoughts such as positive self-talk (Neck \& Houghton, 2006). In this study, we define self-leadership as a group member's ability to lead themselves through the use of behavioral and cognitive strategies.

Self-leadership theorists (e.g., DiLiello \& Houghton, 2006; Houghton \& Yoho, 2005; Neck \& Houghton, 2006) have suggested that creativity and innovation are the predictable outcomes of individual self-leadership. However, research on the relationship between self-leadership, creativity, and innovation is still at the nascent stage. As Neck and Houghton (2006) pointed out, additional research is needed to further clarify the relationship between self-leadership, creativity, and innovation.

Carmeli et al.'s (2006) research found that the self-leadership skill is an antecedent that positively affects innovative behavior. They argued that individual's self-leadership is necessary for the innovation process because innovation in the workplace is a complex process that often entails difficulties, obstacles, and frustration. Not only does the creative individual face a demanding situation in which substantial efforts are required to complete all stages of the innovation process, she or he may also face resistance regarding their efforts and action. This is because people tend to embrace stability and resist insecurity and uncertainty. Hence, given self-leadership's conceptualization as a determinant of innovation, we expect self-leadership to directly affect innovation of group members. Thus: 
Hypothesis 2a Self-leadership positively affects group members' innovation.

Besides self-leadership being a direct influence on innovation, it may also indirectly influence innovation through creativity. According to Houghton and Yoho (2005), self-leadership may mediate the impact of an organization's leadership approach on the creativity of their members. Pearce and Manz (2005) argued that when employees are encouraged to lead themselves in defining problems, making decision, solving problems, and identifying opportunities and challenges both now and in the future, their creativity is encouraged. In contrast, if employees are left to focus on implementing what they are directed to do, then creativity is not encouraged. In addition, Manz and Neck (2004) stated that individuals who have high levels of self-leadership seem likely to evaluate existing standards, and have the ability to set or modify them, thereby fostering creativity and innovation. DiLiello and Houghton's (2008) study supported the theoretical views above. They found that self-leadership significantly and directly affects practiced innovation through creative potential. They concluded that selfleadership is a primary factor for facilitating creativity at all organization levels. Thus, we also expected self-leadership to affect innovation of group members through creativity:

Hypothesis 2b Self-leadership positively affects group members' innovation through creativity.

\section{Creativity mediates the relationship between group culture and group members' innovation}

Somewhat surprisingly, although many authors (e.g., Caldwell \& O'Reilly, 2003; McLean, 2005) have indicated that group culture influences individual creativity as an important resource for innovation, there has been relatively little empirical examination on the mediator role of creativity. Group culture is defined as the way in which members in a group are expected to think and behave in relation both to their tasks and to other people (Cooke \& Rousseau, 1988). Caldwell and O'Reilly (2003) stated that group culture might enhance innovation in groups through norm. According to O'Reilly and Caldwell (1985) and Caldwell and O'Reilly (2003), norms provide social information that individuals use to understand and interpret what they experience at work, including such broad things as the perceived significance of the work. Norms that exist in a group not only shape specific behavior, but also influence much more general type of activities in which a group member engages. Evidence suggests that the group culture that values innovation, active risk taking, and open debate might motivate and direct group members toward creative ideas, which in turn increases the likelihood of an innovation being generated (Hurley, 1995; Tesluk, Farr, \& Klein, 1997). According to this study, the values and norms mentioned above that are shared by a group members are defined as constructive culture. A number of authors hold the view that the constructive culture of an organization can be seen as a critical facilitator of individual innovation (Ahmed, 1998; Mumford, 2000; Mumford \& Simonton, 1997). In contrast, the Thai 
cultural context is a low constructive culture. As Aeimtitiwat (2006) found, top management in Thai firms may have no willingness to take risks from too many solutions. Multiple approaches that may lead to increasing cost, workforce, and time are undesirable for Thai firms. Moreover, failure of projects may be considered as a mistake in Thai enterprises. Thus, in the community products business, there is the possibility that a groups' constructive culture affects group members' innovation. From these theoretical views and evidence, we predict that the degree by which group members perceive the group culture as supportive of risk taking, learning by trial and error, and open communication based on trust would encourage group member's creativity thereby fostering innovation.

Hypothesis 3a Groups' constructive culture positively affects group members' innovation through creativity.

\section{Self-leadership mediates the relationship between group culture and group members' innovation}

Although self-leadership theorists have stated that contextual factors can be encouraged or inhibit self-leadership (Houghton \& Yoho, 2005; Manz, 1986; Pearce \& Manz, 2005), there has been little effort to study the effect of organizational culture on selfleadership. Manz (1986) has stated that individual's self-leadership is amenable to change rather than a fixed trait. Similarly, Pearce and Manz (2005) also suggest that individual self-leadership can be effectively encouraged through organizational reward and training. Based on self-leadership theory evolution, intrinsic motivation is a central part of self-leadership's conceptualization of natural rewards (Manz \& Neck, 2004). The intrinsic motivation can be increased depending on contextual conditions (Shalley, Zhou \& Oldham, 2004). Hence, there is the possibility that constructive culture support of risk taking and learning by trial and error would positively affect the degree of intrinsic motivation of the individual and increase self-leadership, which in turn would foster individual innovation. In contrast, Thai entrepreneurs have a great deal of structuring of organizational activities, more written rules, less risk taking, which in turn contributes to a decrease in the ambitions of employees (Aeimtitiwat, 2006). To test this possibility, we conduct an exploratory analysis of the mediating effect of selfleadership on the relationship between a group's constructive culture and group members' innovation. Thus:

Hypothesis 3b Groups' constructive culture positively affects group members' innovation through self-leadership.

Amabile (2000) and Miron, Erez, and Naveh (2004) argued that high congruence between a creative person and culture results in high level of innovative performance. According to Caldwell and O'Reilly (2003), when groups develop the norm that risk taking is both accepted and encouraged and that mistakes are expected when trying new things, creative individuals are likely to be willing to propose new and creative solutions to problems. This argument is supported by Miron et al.'s (2004) study which found that creative employees who worked in an innovative culture (high autonomy, risk taking, tolerance of mistakes) reached higher 
levels of innovative performance than creative employees in a low innovative culture. In a Thai context, previous evidence suggested that the innovation of Thai employees may be impeded because of the culturally low acceptance of failure (Wongtada \& Rice, 2008) and moderately high uncertainty avoidance (Pornpitakpan, 2000). Thais tend to be concerned with security in life (as opposed to willing to take risks) and believe in experts and their knowledge (as opposed to generalists and common sense) (Pornpitakpan, 2000). Based on the argument above, group constructive culture may act as moderator, which can explain the variation in the relationship between group members' creativity and innovation. Namely, when the level of a group's constructive culture is low, it may lead to a decrease in the perceived opportunity of a member's creativity, and subsequently the relationship between the two is likely to be weaker than when the group culture is perceived as supportive of creativity and innovation. To test this possibility, we conduct an exploratory analysis of the moderating effect of group's constructive culture on the links between group member's creativity and innovation. Thus:

Hypothesis 3c Groups' constructive culture moderates the relationships between group members' creativity and innovation.

According to Mannheim and Halamish (2008), aspects of group culture often moderate the influences of leadership styles. Similarly, Alves, Lovelace, Manz, Matsypura, Toyasaki, and Ke (2006) and D'Intino et al. (2007) have claimed that cultural differences represent important concepts that may affect self-leadership. For example, people in high uncertainty avoidance cultures are more likely to lead themselves in the context of formal plans and rules, while people in low uncertainty avoidance cultures may be more innovative and flexible in their self-leadership. Because of this, organizations with high uncertainty avoidance tend to be more controlling and less approachable (Dickson, Den Hartog, \& Mitchelson, 2003). In contrast, organizations with low uncertainty avoidance cultures value more flexibility, innovation, and job mobility (Dickson et al., 2003). In Pornpitakpan's (2000) study, not only do the Thais appear as having a high uncertainty avoidance culture, they also are moderately collectivistic, in turn this contributes to a weak individual independence, and reliance on the group is expected. Therefore, in this study we propose that constructive culture in the group may play the role of moderator in the relationship between group members' self-leadership and innovation. Yet, few studies have actually tested whether organizational culture empirically moderates selfleadership and individual innovation (DiLiello \& Houghton, 2008), especially in the Asia Pacific region. To test this possibility, we conduct an exploratory analysis of the moderating effect of constructive culture on the self-leadership-innovation link:

Hypothesis 3d Groups' constructive culture moderates the relationships between individual self-leadership and innovation.

\section{Effect of group knowledge management on group members' innovation}

Beckman (1999) defined knowledge management as the formal process that concerns access to experience, knowledge, and expertise that creates new 
capabilities, enables superior performance, encourages innovation, and enhances customer value. To the countries in the Asia Pacific, Peng (2002) and Peng et al. (2008) argued that institution-based knowledge management is the key process that is needed for building differentiated competitive advantage in international business. In this study, we treat the local wisdom as institution-based knowledge. Because Thai local wisdom, such as the knowledge of how to weave silk cloth, to mold pottery, and to carve, is the tacit knowledge that has been passed on from generation to generation. It is an identity and validity for producer groups in Thailand. We define knowledge management as the practice that involves groups' acquiring, capturing, sharing, and using local wisdom and knowledge to enhance their performance and innovation. According to Du Plessis (2007), knowledge management plays an invaluable role in the process of innovation in many ways. First, it provides a focus in the organization on the value of tacit knowledge and assists in creating the environment for tacit knowledge creation, sharing, and leverage to take place. Second, it assists in converting tacit knowledge to explicit knowledge (e.g., handbook and database). Third, it facilitates collaboration in the innovation process. Fourth, it assists in identifying gaps in the knowledge base and provides processes to fill the gaps in order to aid innovation.

At the individual level, only Muhammed et al.'s (2008) study has shown that organizational knowledge management will help increase an individual's understanding of the people (know-who), locations (know-where), and timing (knowwhen) aspects necessary to complete the task, which in turn affects individual innovation. They argued that knowing who the stakeholders are and understanding their needs and expectations can positively contribute to making the outcomes novel and interesting for them. Knowing where he/she can get appropriate resources to accomplish the task, and knowing when to use such information and take appropriate actions can help the individual ease the task of performing those creative actions. In addition, organizational knowledge management is a contextual factor that enables or deters behavior related to how individuals manage their knowledge (e.g., creation, sharing, and application) (Muhammed et al., 2008). An outcome of managing knowledge effectively at the individual level is to have the right knowledge at the right time, so that appropriate values can be added, and workers can enact creative actions (Muhammed et al., 2008). Thus, we expect groups' knowledge management to positively affect group members' innovation:

Hypothesis 4a Groups' knowledge management positively affects group members' innovation.

Most existing literature suggests that organizational knowledge management influences individual creativity, rather than affects directly on individual innovation. As Mumford (2000) argued, in the knowledge management process, an individual will receive new information and get to share a product idea or a way of doing things with other persons. This will help increase comprehension and further improve the new ideas of the individual. Similarly, several authors argued that firms' knowledge management could affect their members' creativity by: (1) increasing individuals' quantity and quality of information (Roffe, 1999), and (2) stimulating individuals to think critically and creatively (Lindsey, 2006) and possibly dealing directly with 
cognitive biases (Houghton, Simon, Aquino, \& Goldberg, 2000). In addition, previous studies have shown that knowledge sharing positively affects individual creativity (Teigland \& Wasko, 2003) and constructive controversy among team members can facilitate risk taking that, in turn, promotes innovation (Tjosvold \& Yu, 2007). Based on the argument and results above, creativity may act as mediator in the linkage of groups' knowledge management and group members' innovation. Thus:

Hypothesis 4b Groups' knowledge management positively affects group members' innovation through creativity.

\section{Methods}

Sample and data collection procedure

The sample for this study consisted of 1,526 members from 138 producer groups (812 persons per group) in 19 provinces in Northeast Thailand. As suggested by Maas and Hox (2005), we determined the minimum sample size at the group level $(n>$ 100) needed for accurate estimation of the multilevel modeling. The number of participants in each group depended on the number of group members who volunteered to be interviewed. Proportional stratified random sampling from 19 provinces was used. The names of producer groups were drawn from the list of 1,081 names registered with the Office of Committee of Standardized Industrial Products, Ministry of Industry (Thai Tambon, 2009). Potential participants were contacted by researchers who discussed the study. If producer groups were willing to take part, an appointment was made to interview them in their own office. To reduce interviewer bias, the data were collected by 19 research assistants, who were undergraduate students, majoring in business management in the faculty of Accountancy and Management, Mahasarakham University. These assistants were local people in provinces in which the participating producer groups lived. They received considerable training including lectures on the importance of asking the questions in the order and in the very same manner as on the questionnaire, and one-on-one role-playing sessions with an experienced interviewer. A structural interview survey approach was used because we anticipated a low response rate from a postal survey. Interviewer bias was detected by comparing the mean of all variables from the responses of 19 interviewers with an analysis of the variance technique. Only 7 out of 171 pair-wises showed a significantly different mean for group member innovation, while no significant difference was found between 19 interviewers within the data of the rest of the variables. Thus, the interviewer bias effect was not a concern.

Overall, 1,372 participants (89.9\%) were women and 154 participants $(1.1 \%)$ were men. The age of the participants ranged from 17 to 61 years $($ mean $=42.7)$. Six hundred and forty four (42.2\%) had an education lower than high-school level, 886 participants $(57.8 \%)$ had an education at the high-school level or higher. The participants had a group tenure ranging from 0.25 to 20 years $($ mean $=6.77)$. 
Fifty-seven producer groups $(41.3 \%)$ produced textile and garment products. Thirty-three $(23.9 \%), 21(15.2 \%)$, and $11(7.9 \%)$ of the producer groups produced foods products, decorative ornaments products, and created arts and souvenirs products, respectively. Sixty-four of the producer groups (46.4\%) received formal branding as five star products (highest quality level and exportable). Forty producer groups (29\%) received formal branding with a four star products (domestically acceptable and can be developed to be exportable products) and the rest, 34 producer group (24.6\%) received formal branding as three star products (medium quality which can be developed to 4-5 star products). Seventy-five of the producer groups $(54.4 \%)$ had less than 30 members and the rest $(45.6 \%)$ had more than 30 members. The average duration of operations was 10.12 years (ranging from 1 to 21 years).

\section{Measures of key constructs}

Almost all constructs in this study were measured based on a 5-point Likert scale, that ranged from 1 (strongly disagree) to 5 (strongly agree). The innovation constructs were measured based on a yes (1) or no (0) response. The underlying dimensions for all constructs were explored by using the exploratory factor analysis (EFA). The results of EFA in all constructs showed that the items assessed only one underlying dimension. Items used to measure the main constructs are presented in the Appendix and the other details are described in the section below.

Groups' constructive culture The scale to measure groups' constructive culture was adapted from the constructive culture scale developed and validated by Cooke and Rousseau (1988). The scale contained seven items, measuring the way in which producer group members are expected to think and behave in relation to their tasks and to other people. Factor loading of the items ranged from 0.65 to 0.74 . Reliability was acceptable (alpha $=0.87$ ). A higher score on this construct indicated a more constructive culture.

Groups' knowledge management The scale to measure groups' knowledge management was created based on the operationalization of the variable and knowledge management scale of Darroch and McNaughton (2002). The scale contained eight items, measuring practices that involved acquiring, capturing, sharing, and using local wisdom and knowledge to enhance group performance. Factor loading of the items ranged from 0.54 to 0.73 . Reliability of the measure was acceptable (alpha=0.82). A higher score indicated a higher level of knowledge management practices.

Creativity The scale to measure creativity among a group's members was adapted from the employee creative behavior scale developed and validated by Rice (2006). The scale contained six items, measuring the individual's ability to generate new and useful ideas. Factor loading of the items ranged from 0.56 to 0.74 . Reliability of the measure was acceptable (alpha=0.85). A higher score on this construct indicated greater creativity. 
Self-leadership The scale to measure a group member's self-leadership was adapted from the self-leadership questionnaire developed and validated by Houghton and Neck (2002). The scale contained seven items, measuring the individual's leading oneself through the use of specified sets of behavioral and cognitive strategies. Although Houghton and Neck's (2002) self-leadership scale consists of three underlying dimensions, an EFA in this study showed that the items assessed only one underlying dimension. Factor loading of the items ranged from 0.59 to 0.69 . Reliability of the measure was acceptable (alpha=0.84). A higher score on this construct indicated greater self-leadership.

Group members' innovation The scale to measure innovation among group members was adapted from the innovation output scale ( Ju, Li, \& Lee, 2006; Vermeulen, O'Shaughnessy, \& de Jong, 2003). The scale contained six items, measuring product and work process innovation in the past three years, because previous studies indicated that more than 50 percent of community product producers have been able to improve their new products during the past three years (Stam, de Jong, \& Marlet, 2008). Factor loading of the items ranged from 0.66 to 0.81 . Reliability was acceptable (alpha=0.88). A higher score on this construct indicated greater innovation.

Control variables To control for the possibility that socio-demographic differences in the predictors at the individual level and outcome variables might lead to biased regression coefficients, gender $(0=$ male; $1=$ female), age (in years), education level $(0=$ lower than high school, $1=$ high school or higher), and group tenure (in years) were entered as covariates in an analysis. We did this because previous researches have shown creativity/innovative behavior are significantly relate to these demographic variables (Baer, Oldham, \& Cummings, 2003; Scott \& Bruce, 1994).

Data analysis

Data in this study were analyzed by multilevel modeling, which allowed for the analysis of individual- and group-level data simultaneously without the shortcoming of aggregation and disaggregation (Hofmann, Griffin, \& Gavin, 2000). It is also effective for modeling cross-level interaction effects between group-level predictors and individual-level predictors on outcome variables (Hofmann et al., 2000). In this study, eight models were constructed for predicting group members' innovation. We started Model 0 with a null model: there were no independent variables both the individual and the group level. The information estimated in the null model is used to compute the intraclass correlation coefficient (ICC) that is used for indicating the amount of variance in the innovation of group members that could potentially be explained by the group's constructive culture and knowledge management. Results from testing this model should be satisfied (ICC $>0$ ) before conducting cross-level analyses. For Model 1, we added group members' creativity, self-leadership, and the error variance in the intercepts and slopes to the null model. In this model, if there is significant difference in group variance, then group's constructive culture and knowledge management effects would exist. In Model 2, we introduced groups' constructive culture and knowledge management to the group-level intercept in 
Model 0. Based on results from this model, we could conclude whether even after including group's constructive culture and knowledge management, significant variance remained in the intercept term across groups that could be explained by additional group-level variables. A significant condition must exist in order to test for moderators. In order to test mediation effect, we also ran four separate models (Models 3, 4, 7, and 8). In Model 3, only creativity was introduced as an independent variable, whereas in Model4, only self-leadership was introduced. In Model 7 and 8, creativity and self-leadership were treated as the individual-level outcomes. Results from estimating Models 1, 3, 4, 7, and 8 were used to examine Baron and Kenny's (1986) precondition for mediation. Then, to test for the mediation effect of variables that are able to meet the preconditions, we used a Model 5, by adding mediator and control variables as the individual-level predictors. Full mediation occurs when the regression coefficient of groups' constructive culture and knowledge management on group member innovation is reduced to zero; otherwise, the mediating effect is partial. For Model 6, we added groups' constructive culture and knowledge management to the group-level slopes in Model 1. This model was a direct test for cross-level moderating effects (Wech \& Heck, 2004).

\section{Results}

Table 1 reports means, standard deviations, and correlation among variables included in the analysis. Results revealed that age, education level, and group tenure correlated with self-leadership, creativity, and group members' innovation. Thus, these variables are treated as a covariate for individual-level analysis, because failing to control for relevant variables that are correlated with included variables leads to biased beta coefficients and sometimes to the opposite results than may exist in the population.

Table 2 includes the correlation matrix between aggregated individual-level variables and group-level variables $(n=138)$. Results revealed that group duration of operations correlated with creativity and groups' knowledge management $(r=0.25$ and $0.21, p<0.01$ and 0.05 , respectively). However, it was not correlated with innovation of group members. Thus, the duration of operation is not treated as a control variable for group-level analysis.

In Model 0 the ICC was computed. The ICC value revealed that $51.9 \%$ of the total variance in innovation of group members could potentially be explained by the group-level predictor variables. The chi-square statistic for group member innovation showed that significant variability in the mean for innovation of group members existed across groups $\left(\chi^{2}=1,805, p<0.001\right)$. This suggests that the development of a multilevel model is warranted.

From Table 3, Model 1 estimations indicated that creativity significantly affects innovation of group members $(\beta=0.168, p<0.01)$, which supports Hypothesis 1 . The regression coefficient for group tenure (control variable) was .01, which was small but significant. Self-leadership did not positively affect innovation of group members $(\beta=0.03, p=n s)$. Therefore, Hypothesis 2 was not supported. However, Models 1, 3, and 4 indicated that Baron and Kenny's (1986) three preconditions for 
Table 1 Descriptive statistics and correlation matrix for individual level variables.

\begin{tabular}{|c|c|c|c|c|c|c|c|c|}
\hline Variables & Mean & S.D. & 1 & 2 & 3 & 4 & 5 & 6 \\
\hline 1. Gender & .91 & .29 & & & & & & \\
\hline 2. Age & 42.70 & 10.30 & .04 & & & & & \\
\hline 3. Education level & .57 & .49 & $.07 * *$ & $.08^{* *}$ & & & & \\
\hline 4. Group tenure & 6.77 & 3.67 & .01 & $.61 * *$ & .03 & & & \\
\hline 5. Creativity & 3.84 & .60 & -.02 & $.09^{* *}$ & $.18^{* *}$ & $.16^{* *}$ & & \\
\hline 6. Self-leadership & 3.93 & .58 & .01 & $.08 * *$ & $.30 * *$ & $.14 * *$ & $.53 * *$ & \\
\hline 7. Group members' innovation & .73 & .23 & .04 & $.20 * *$ & $.14^{* *}$ & $.32 * *$ & $.46^{* *}$ & $.57 * *$ \\
\hline
\end{tabular}

$n=1,526 ; * * p<.01$.

the indirect effect were met for self-leadership (Hypotheses 2b). Results from Table 3, Model 1 revealed that when creativity and self-leadership were entered together into the equation predicting innovation of group member, self-leadership had no significant effect. These results suggested that self-leadership fully mediated the effects of group's constructive culture. According to MacKinnon, Fairchild, and Fritz (2007), the value of the indirect effect was estimated by taking the difference in the coefficients, $\gamma_{20 \text { Model } 1}-\gamma_{20 \text { Model4 }}$. For testing the significance of the indirect effect, the difference was then divided by Sobel's standard error and the ratio ( $t$-statistic) was compared to a standard normal distribution. Therefore, the indirect effect of selfleadership on innovation equaled $0.088-0.03=0.058(t=6.59, p<0.05)$.

Results from the Model 2 estimation found that groups' constructive culture and knowledge management positively influenced innovation of group members $(\beta=0.075$ and 0.109 , respectively, $p<0.01$ ), and supported Hypothesis $4 \mathrm{a}$. When comparing the estimates of the residual variance produced in Model 0 and Model 2, it showed that groups' constructive culture and knowledge management explained $22 \%$ of the variance in innovation among group members.

The estimating Models 1, 7, and 8 revealed that Baron and Kenny's (1986) three preconditions for mediation were met for creativity (Hypotheses 3a and 4b), but not for self-leadership (Hypothesis $3 b$ ). This was because self-leadership was

Table 2 Descriptive statistics and correlation matrix for group level variables.

\begin{tabular}{|c|c|c|c|c|c|c|c|}
\hline Variables & Mean & S.D. & 1 & 2 & 3 & 4 & 5 \\
\hline 1. Duration of operation & 10.12 & 4.17 & & & & & \\
\hline 2. Creativity & 3.84 & .45 & $.25 * *$ & & & & \\
\hline 3. Self-leadership & 3.93 & .44 & .10 & $.67 * *$ & & & \\
\hline 4. Constructive culture & 3.46 & .52 & .04 & $.26^{* *}$ & $.54 * *$ & & \\
\hline 5. Knowledge management & 3.60 & .50 & $.21 *$ & $.42 * *$ & $.59 * *$ & $.21 * *$ & \\
\hline 6. Group members' innovation & .73 & .17 & .08 & $.62 * *$ & $.64 * *$ & $.30 * *$ & $.36 * *$ \\
\hline
\end{tabular}

$n=138 ; * p<.05, * * p<.01$ 


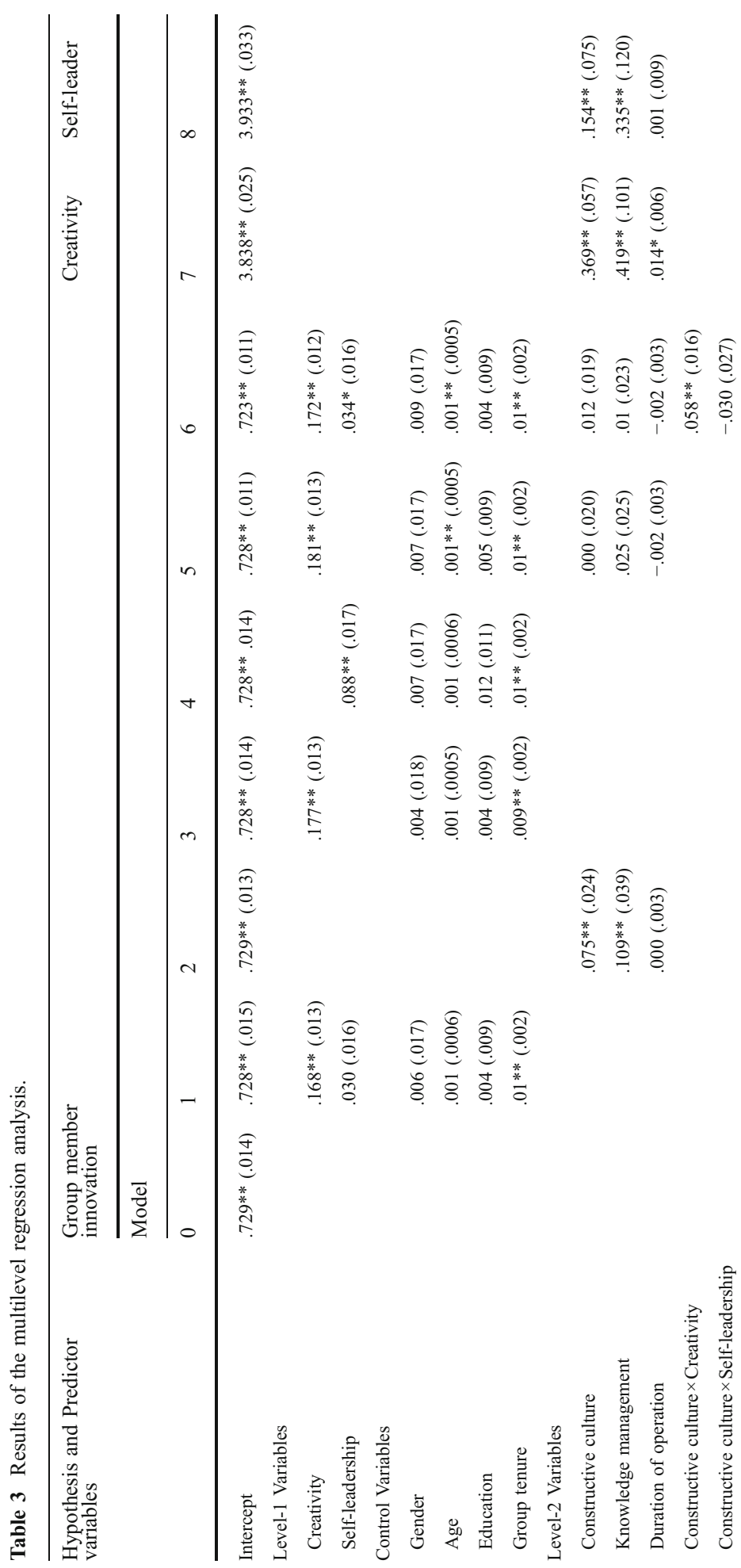




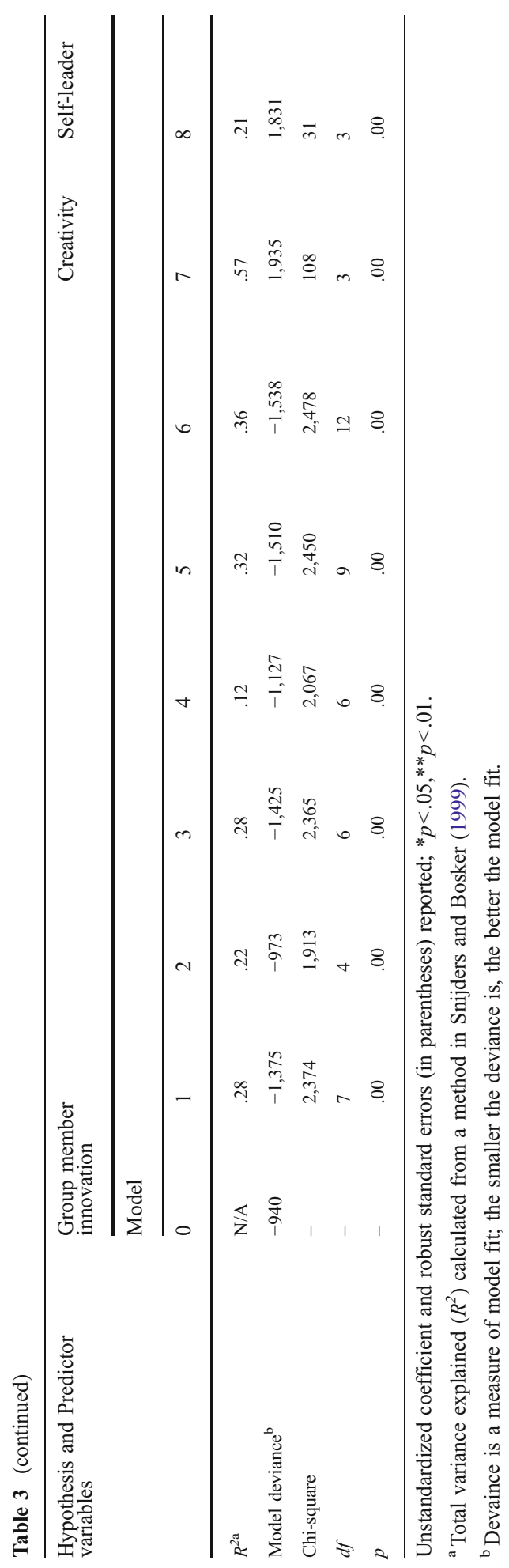


not significantly related to innovation of group members (see Model 1). Thus, we only tested for the mediating effect specified in Hypothesis $3 \mathrm{a}$ and $4 \mathrm{~b}$. Model 5 suggested that creativity had a strong mediating effect, and fully mediated the effects of groups' constructive culture and knowledge management. The value of the mediated effect of creativity on groups' constructive culture linked with the innovation of group members equaled $0.075-0.00=0.075(t=3.04, p<0.01)$ and on group's knowledge management linked with the innovation of group members $0.109-0.025=0.083(t=2.59, p<0.01)$. Comparing Model 5 to Model 0 , the $R$ square at the group level and the individual level was 0.44 and 0.32 respectively. This means that group-level predictors (constructive culture and knowledge management) and individual-level predictors (creativity and self-leadership) accounted for $44 \%$ and $32 \%$ of the variance in the innovation of a group member, respectively.

Regarding cross-level interaction, the results of the Model 6 estimation in Table 3 suggested that groups' constructive culture significantly moderated the relationships between group members' creativity and innovation $\left(\gamma_{11}=0.058, p<0.01\right)$. We checked the cross-level interaction, using group mean centering to ensure that the results were not spurious as recommended by Hofmann et al. (2000). The result revealed that cross-level interaction was significant and approximate value. This supported Hypothesis 3c. This suggested that the effect of creativity on a group member's innovation depended on the degree of constructive culture in a group. To interpret this interaction further, an unstandardized coefficient of the association of creativity with group constructive culture was computed as suggested by Ping (2002) and presented in Table 4. From Table 4, when the existing level of group constructive culture was low in Column 1 (constructive culture $=1.66,2,3$ ), the regression coefficient for creativity was low and was not significant (see Columns 4 and 5). In contrast, when group constructive culture was high (equal or above its study average for the sample), the regression coefficient for creativity was high and significant. Results have also shown that Model 6 could explain 36\% of the total variance in innovation among group members. In addition, the estimates of the residual slope variance $\left(\sigma_{e}^{2}\right)$ produced in Model $5(0.017)$ (after controlling for creativity and covariates) and residual intercept variance $\left(\sigma_{u}^{2}\right)$ in Model $6(0.014)$ (Wech \& Heck, 2004) were compared. The $R$-square for cross-level interaction was $\left(\sigma_{e_{\text {Model } 5}}^{2}-\sigma_{u_{\text {Model }}}^{2}\right) / \sigma_{u_{\text {Model }}}^{2}=(0.017-0.014) / 0.015=0.20$, suggesting that $20 \%$ of variance in the relationship between creativity and innovation of group members was accounted for by groups' constructive culture. However, no support was found for the assertion that groups' constructive culture moderates the relationship between selfleadership and innovation of group members (Hypothesis 3d).

In summary, six of the nine hypotheses involving group members' innovation were supported. The significant, positive path between group members' creativity and innovation, between group members' self-leadership and innovation through creativity, between groups' constructive culture and group members' innovation through creativity, between groups' knowledge management and creativity, between groups' knowledge management and members' innovation through creativity, and groups' constructive culture moderated the effect of members' creativity on innovation, fully supporting Hypotheses $1,2 \mathrm{a}, 3 \mathrm{a}, 3 \mathrm{c}, 4 \mathrm{a}$, and $4 \mathrm{~b}$, respectively. No support was found for Hypothesis 2a (the direct effect of group members' self- 
Table 4 Unstandardized coefficients of creativity associations with groups' constructive culture level.

\begin{tabular}{lcccr}
\hline Constructive culture level & Creativity coefficients & SE & $t$ & $p$-value \\
\hline $4.57^{\mathrm{a}}$ & .136 & .032 & 4.258 & .000 \\
4 & .105 & .026 & 4.011 & .000 \\
$3.46^{\mathrm{c}}$ & .075 & .024 & 3.125 & .002 \\
3 & .049 & .025 & 1.924 & .054 \\
2 & -.005 & .036 & -.144 & .885 \\
$1.66^{\mathrm{b}}$ & -.024 & .042 & -.574 & .567 \\
$(1)$ & $(2)$ & $(3)$ & $(4)$ & $(5)$ \\
\hline
\end{tabular}

${ }^{a}$ Maximum value; ${ }^{b}$ Minimum value; ${ }^{\mathrm{c}}$ Mean value.

leadership on innovation), Hypotheses $3 b$ (self-leadership mediates the impact of group's constructive culture on group members' innovation), and Hypotheses $3 \mathrm{~d}$ (group's constructive culture moderates the impact of members' self-leadership on innovation).

\section{Discussion}

The present study supports two assumptions of the Person-Environment Fit theory. Namely, our findings imply that group members' innovation is a joint function of individual creativity and self-leadership, group constructive culture, and knowledge management.

At the individual level, results added to our understanding about the nature of relationships among the self-leadership, creativity, and innovation. Our findings showed that self-leadership indirectly affected the innovation of group members via creativity, rather than directly affected their innovation. Additionally, this study implied that self-leadership of group members of community product producers may have depended on age or personality traits more than on group culture. D'Intino et al. (2007) and Williams, Verble, Price, and Layne (1995) have argued that a variety of personality traits and personal factors (e.g., age and gender) significantly relate to self-leadership. In this study, all participants were local people who tended to have low trait preference of extraversion and internal locus of control (they believed that they had little control over their outcomes), while having high conformity (Pornpitakpan, 2000). These personal traits may relate to self-leadership of participants more than group culture. However, results demonstrated that gender was not correlated with self-leadership. Age was significantly correlated, but very small. To clarify the relationships among these variables, more research is warranted.

At the group level, both group-level factors have an indirect influence on the group members' innovation through creativity. The results found that a group's constructive culture moderated the relationship between group members' creativity and innovation. Within small groups, group members of community product producers can frequently interact with each other. The day-to-day interactions 
among members may lead to learning about what kind of behavior is acceptable and how activities should function in a producer group. Thus, if the group values innovation and supports risk taking, group members are more likely to be creative in their thinking, and more willing to experiment with new ideas. Consequently, innovation among group members will be developed further. Furthermore, higher groups' constructive culture may act as a contextual catalyst for the innovative processes, making it easier for creative members to act on their tendency to demonstrate creative behavior towards other group members. This is consistent with previous works (e.g., Caldwell \& O'Reilly, 2003; Miron et al., 2004; Schilling, 2008).

Results also indicated that group knowledge management affected innovation of group members through creativity. This may be due to the fact that group knowledge management not only deals with cognitive biases and fills the gaps in the local wisdom of group members, but the new information and knowledge that is obtained during knowledge management practices also encourages novel ideas and alternative solutions. These members' creative thinking leads to new beneficial products and work processes. As Du Plessis (2007) stated, tacit knowledge management as a resource for innovation is important in developing fields where not a lot of explicit knowledge exists. Thai producer groups of community products are regarded as organizations where not a lot of formal knowledge exists; almost all knowledge is local wisdom or tacit knowledge that has been passed on from generation to generation.

As a result, the present study contributes to the innovation literatures by filling the gap and adding the understandings of the group- and individual-level factors affecting group members' innovation, particularly in the community product business and in the Thai context. One shortcoming of existing innovation research is the tendency to study innovation at the organizational level and be limited to only a single level of analysis (Anderson et al., 2004; Yuan, 2005). In addition, as noted by Lu et al. (2008), research on knowledge management and innovation based on an institution-based view in the Asia Pacific region is still in a developmental stage, and the results of our examination of the link between group's local knowledge management and group members' innovation also fulfill the gap of existing research in this area.

Our findings offer guidance on the practical implications in at least two ways. First, results indicated that group's knowledge management is the best predictor of a group members' innovation through creativity. This suggests that community product producers should engage in the knowledge management practices in order to promote group members' creativity and subsequently improve group members' innovation. Transferring, sharing, and capturing local wisdom with the government officials and local universities may lead to an improvement in the quality and quantity of knowledge and information of group members, conversion of tacit knowledge to explicit knowledge, and also assist group members in identifying gaps in their local wisdom and provide a collaborative process for developing their innovation. Consistent with previous research in the Asia Pacific region, this study found that knowledge exploitation and exploration (Isobe, Makino, \& Montgomery, 2008) and ties between companies and universities (Gao, Xu, \& Yang, 2008; Su, Tsang, \& Peng, 2009) significantly affected firm performance. Consistent with Su et 
al. (2009), the external partnerships (e.g., universities and research institutions) seem to add value and contribute to innovativeness of firms. Second, our results also indicated that group's constructive culture factor determines whether group member with high creative thinking will be successful innovators. Fostering a risk taking atmosphere, taking autonomous action by learning from mistakes, and valuing innovation, based on trust, are the factors that will encourage group members more to enact their creative ideas and to experiment with new solutions. Consequently, innovation will be created in the group.

\section{Limitations and future research directions}

Although we have achieved some useful results, we are aware of the limitations of this study. First, the issue of common method variance resulting from predictors and criterion variables were measured as individual perceptions with a common method and source. To reduce common method variance, we followed the recommendations of Podsakoff, MacKenzie, Lee, and Podaskoff (2003). We minimized the problem by using different response formats for the measurement of the predictors and criteria variable. While all predictors were measured based on a 5-point Likert scale response, the criteria variables (group members' innovation) were measured based on a "yes" or "no" response. We aggregated constructive culture and knowledge management as a group-level variable, which helped reduce the potential for spurious results based on individual-level observed variance (Tse, Dasborough, \& Ashkanasy, 2008). In addition, we also conducted EFA by including all items from all of the constructs in this study into an analysis and found seven factors emerging. The CFA results demonstrated that the one-factor structure did not fit the data. Hence, it seems that the common method effect did not significantly influence the findings. Second, the group members' innovation was a self-reported measure. This may have lead to over-reporting of innovation of group members under the influence of social desirability bias. Future research should strive to obtain member innovation evaluation from multiple raters, including group members themselves, peers, and group leaders; high correlation among group members' innovation from these sources of rating will help us more confidently conclude our results. Finally, this study employed a cross-sectional design; the results cannot be interpreted as causal. Future research should examine how these relationships develop over time, by using tools such as experimental or longitudinal design.

\section{Conclusions}

In summary, although research has emphasized the importance of individual creativity and self-leadership, group's constructive culture and knowledge management for innovation, few past studies have examined the mediation and moderation relationships among these variables, especially in a Thai context. Our findings fill this gap by revealing that self-leadership, group's constructive culture and knowledge management indirectly affect group members' innovation. It also suggests that the group's constructive culture positively moderates the effects of creativity on group members' innovation. 
Open Access This article is distributed under the terms of the Creative Commons Attribution Noncommercial License which permits any noncommercial use, distribution, and reproduction in any medium, provided the original author(s) and source are credited.

\section{Appendix}

Measurement items in questionnaire

\section{Groups' constructive culture}

1. My co-workers value an innovation.

2. My co-workers emphasize on quality over quantity.

3. My co-workers support taking risks.

4. My co-workers support trying new ideas and approaches.

5. My co-workers emphasize on product improvement meeting customer's needs.

6. My co-workers consider everybody's ideas and contributions are respected.

7. My co-workers belief that novel products will help group survival.

Groups' knowledge management

1. My group survey customer's preference before produce the products based on group local wisdom.

2. My group encourages all members to acquire new approaches and technology for local wisdom development.

3. My group provides a meeting to exchange knowledge and experience for product development among members.

4. My group shares knowledge and experience with the university and government officials in order to fill the gaps in the local wisdom of group members.

5. My group cooperates with other enterprise to develop new products and channel distribution.

6. My group provides a meeting to transfer the new technology and knowledge for product development to the members.

7. My group has the computer system for store the group's local wisdom.

8. My group captures and uses local wisdom in order to develop differentiated products.

Group members' creativity

1. I can produce new products based on recombine existing local wisdom in new ways.

2. I generated ideas for new products rather more frequently than the other members.

3. I produce ideas about unique products from integration of the new technology with local wisdom.

4. I think about new raw material and approaches that can be used to develop the quality of products.

5. I present the ideas of new channel distribution that differs from other producers.

6. I present the ideas of new approach to increase the speed of group's production and distribution.

Group members' self-leadership

1. I visualize myself successfully performing a task before I do it. 
2. When I'm in difficult situation of production and distribution, I will sometimes talk to myself to help me get through it.

3. I try to think of positive changes that will happen from effort to develop product quality and channel distribution.

4. I pay attention to how well I'm doing in my work.

5. When I have a problem in the part of my responsibilities, I will attempt to solve it myself.

6. I try to think of increasing sales volume of my group.

7. I focus my thinking on the pleasant rather than the unpleasant aspects of my job activities.

Group members' innovation

1. In the past three years, did you introduce products or service new for the Thailand market to the group?

2. In the past three years, did you introduce products or services new for the foreign market to the group?

3. In the past three years, did you introduce production methods that reduced the costs of the group?

4. In the past three years, did your group possess product patent that it is initiated by you?

5. In the past three years, did you refine and extends an existing products that help group make a profit?

6. In the past three years, did you initiate and develop new service that help group have advantage competitive over competitors?

\section{References}

Aeimtitiwat, P. 2006. Corporate entrepreneurship characteristics and organizational innovativeness of large enterprises in Thailand. Unpublished doctoral dissertation, Bangkok University, Bangkok, Thailand.

Ahmed, P. K. 1998. Culture and climate for innovation. European Journal of Innovation Management, 1: $30-43$.

Alves, J. C., Lovelace, K. J., Manz, C. C., Matsypura, D., Toyasaki, F., \& Ke, K. 2006. A cross-cultural perspective of self-leadership. Journal of Managerial Psychology, 21: 338-359.

Amabile, T. M. 1999. How to kill creativity: Harvard business review on breakthrough thinking. Boston: Harvard Business School Publishing.

Amabile, T. M. 2000. Stimulate creativity by fueling passion. In E. Locke (Ed.). Handbook of principle of organizational behavior: 331-341. Malden, MA: Blackwell.

Amabile, T. M., Conti, R., Coon, H., Lazenby, J., \& Herron, M. 1996. Assessing the work environment for creativity. Academy of Management Journal, 39: 1154-1184.

Anderson, N., De Dreu, C. K. W., \& Nijstad, B. A. 2004. The routinization of innovation research: A constructively critical review of the state-of-the-science. Journal of Organizational Behavior, 25: $147-172$.

Aulawi, H., Sudirman, I., Suryadi, K., \& Govindaraju, R. 2009. Knowledge sharing behavior, antecedent and their impact on the individual innovation capability. Journal of Applied Science Research, 5: 2238-2246.

Baer, M., Oldham, G. R., \& Cummings, A. 2003. Rewarding creativity: When does it really matter?. Leadership Quarterly, 14: 569-586.

Baron, R. M., \& Kenny, D. A. 1986. The moderator-mediator variable distinction in social psychological research: Conceptual, strategic, and statistical considerations. Journal of Personality and Social Psychology, 51: 1173-1182. 
Beckman, T. J. 1999. The current state of knowledge management. In J. Liebowitz (Ed.). Knowledge management handbook: 1-22. Boca Raton, LA: CRC Press LLC.

Caldwell, D. F., \& O'Reilly, C. A. 2003. The determinants of team-based innovation in organizations: The role of social influence. Small Group Research, 34: 497-517.

Carmeli, A., Meitar, R., \& Weisberg, J. 2006. Self-leadership skills and innovative behavior at work. International Journal of Manpower, 27: 75-90.

Chutiwanichayakul, W. 2005. Creative entrepreneurship in Asia. Country paper (Thailand 2), Asian Productivity Organization, Tokyo, Japan.

Cooke, R. A., \& Rousseau, D. M. 1988. Behavioral norms and expectations: A quantitative approach to the assessment of organizational culture. Group and Organization Studies, 13: 245-273.

Cummings, A., \& Oldham, G. R. 1997. Enhancing creativity: Managing work contexts for the high potential employee. California Management Review, 40: 22-38.

Darroch, J., \& McNaughton, R. 2002. Examining the link between knowledge management practices and types of innovation. Journal of Intellectual Capital, 3: 210-222.

Dickson, M. W., Den Hartog, D. N., \& Mitchelson, J. K. 2003. Research on leadership in a cross-cultural context: Making progress, and raising new questions. Leadership Quarterly, 14: 729-768.

DiLiello, T. C., \& Houghton, J. D. 2006. Maximizing organizational leadership capacity for the future: Toward a model of self-leadership, innovation and creativity. Journal of Managerial Psychology, 21: 319-337.

DiLiello, T. C., \& Houghton, J. D. 2008. Does organizational level influence self-leadership in the defense acquisition workforce?. http://www.thefreelibrary.com/Doesorganizationallevelinfluenceselfleadershipinthedefense...-a0183489513, Accessed Aug. 25, 2010.

D'Intino, R. S., Golgsby, M. G., Houghton, J. D., \& Neck, C. P. 2007. Self-leadership: A process for entrepreneurial success. Journal of Leadership and Organizational Studies, 13: 105-120.

Du Plessis, M. 2007. The role of knowledge management in innovation. Journal of Knowledge Management, 11: 20-29.

Gao, S., Xu, K., \& Yang, J. 2008. Managerial ties, absorptive capacity, and innovation. Asia Pacific Journal of Management, 25(3): 395-412.

Heye, D. 2006. Creativity and innovation: Two key characteristics of the successful 21st century information professional. Business Information Review, 23: 252-257.

Hofmann, D. A., Griffin, M. A., \& Gavin, M. B. 2000. The application of hierarchical linear modelling to organizational research. In K. J. Klein \& S. W. Kozlowski (Eds.). Multilevel theory, research, and methods in organizations: Foundation, extensions, and new directions: 467-511. San Francisco: Jossey-Bass.

Houghton, J. D., \& Neck, C. P. 2002. The revised self-leadership questionnaire: Testing a hierarchical factor structure for self-leadership. Journal of Managerial Psychology, 17: 672-691.

Houghton, J. D., \& Yoho, S. K. 2005. Toward a contingency model of leadership and psychological empowerment: When should self-leadership be encouraged?. Journal of Leadership \& Organizational Studies, 11: 65-83.

Houghton, S. M., Simon, M., Aquino, K., \& Goldberg, C. B. 2000. No safety in numbers: Persistence of biases and their effects on team risk perception and team decision making. Group \& Organization Management, 25: 325-353.

Hurley, R. F. 1995. Group culture and its effect on innovative productivity. Journal of Engineering and Technology Management, 12: 57-75.

Isobe, T., Makino, S., \& Montgomery, D. 2008. Technological capabilities and firm performance: The case of small manufacturing firm in Japan. Asia Pacific Journal of Management, 25(3): 413-428.

Janssen, O., Van de Vliert, E., \& West, M. 2004. The bright and dark sides of individual and group innovation: A special issue introduction. Journal of Organizational Behavior, 25: 129-145.

Ju, T. L., Li, C. Y., \& Lee, T. S. 2006. A contingency model for knowledge management capability and innovation. Industrial Management \& Data Systems, 106: 855-877.

Lindsey, K. L. 2006. Knowledge sharing barriers. In D. G. Schwartz (Ed.). Encyclopedia of knowledge management: 499-506. Hershey, PA: Idea Group.

Lu, Y., Tsang, E. W. K., \& Peng, M. W. 2008. Knowledge management and innovation strategy in the Asia Pacific: Toward an institution-based view. Asia Pacific Journal of Management, 25(3): 361-374.

Maas, C. J. M., \& Hox, J. J. 2005. Sufficient sample sizes for multilevel modeling. Methodology, 1: 86-92.

MacKinnon, D. P., Fairchild, A. J., \& Fritz, M. S. 2007. Mediation analysis. Annual Review of Psychology, 58: 593-614.

Madjar, N. 2005. The contributions of different groups of individuals to employees' creativity. Advances in Developing Human Resource, 7: 182-206. 
Mannheim, B., \& Halamish, H. 2008. Transformational leadership as related to team outcomes and contextual moderation. Leadership \& Organization Development Journal, 29: 617-630.

Manz, C. C. 1986. Self-leadership: Toward an expanded theory of self-influence process in organizations. Academy of Management Review, 11: 585-600.

Manz, C. C., \& Neck, C. P. 2004. Mastering self-Leadership: Empowering yourself for personal excellence, 3rd ed. Upper Saddle River, NJ: Pearson Prentice-Hall.

Manz, C. C., \& Sims, H. P., Jr. 1989. Superleadership: Leading others to lead themselves. Englewood Cliffs: Prentice-Hall.

McLean, L. D. 2005. Organizational culture's influence on creativity and innovation: A review of the literature and implications for human resource development. Advances in Developing Human Resources, 7: 226-246.

Miron, E., Erez, M., \& Naveh, E. 2004. Do personal characteristics and cultural values that promote innovation, quality, and efficiency compete or complement each other?. Journal of Organizational Behavior, 25: 175-199.

Muhammed, S., Doll, W. J., \& Deng, X. 2008. Exploring the relationship among individual knowledge management outcomes. Paper presented at the Proceedings of the $41^{\text {st }}$ Annual Hawaii International Conference on System Science, Hawaii, January.

Mumford, M. D. 2000. Managing creative people: Strategies and tactics for innovation. Human Resource Management Review, 10: 313-351.

Mumford, M. D., \& Simonton, D. K. 1997. Creativity in the workplace: People, problems, and structures. Journal of Creative Behavior, 31: 1-7.

Neck, C. P., \& Houghton, J. D. 2006. Two decades of self-leadership theory and research: Past developments, present trends, and future possibilities. Journal of Managerial Psychology, 27: 270-296.

Oldham, G. R., \& Cummings, A. 1996. Employee creativity: Personal and contextual factors at work. Academy of Management Journal, 39: 607-634.

O'Reilly, C. A., \& Caldwell, D. F. 1985. The impact of normative social influence and cohesiveness on task perception and attitudes: A social information processing approach. Journal of Occupational Psychology, 58: 193-206.

Parzefall, M. R., Seeck, H., \& Leppänen, A. 2008. Employee innovativeness: A review on the antecedents. Finnish Journal of Business Economics, 2: 165-182.

Pearce, C. L., \& Manz, C. C. 2005. The new silver bullets of leadership: The importance of self- and shared leadership in knowledge work. Organizational Dynamics, 34: 130-140.

Peng, M. W. 2002. Towards an institution-based view of business strategy. Asia Pacific Journal of Management, 19(2-3): 251-267.

Peng, M. W., Wang, D., \& Jiang, Y. 2008. An institution-based view of international business strategies: A focus on emerging economies. Journal of International Business Studies, 39: 920-936.

Ping, R. A. 2002. Interpreting latent variable interactions. Paper presented at the American Marketing Association Winter Educators' Conference Proceedings, Chicago.

Podsakoff, P. M., MacKenzie, S. B., Lee, J. Y., \& Podaskoff, N. P. 2003. Common method biases in behavioral research: A critical review of the literature and recommended remedies. The Journal of Applied Psychology, 88: 879-903.

Pornpitakpan, C. 2000. Trade in Thailand: A three-way cultural comparison. Business Horizons, 43: 6170.

Rice, G. 2006. Individual values, organizational context, and self-perceptions of employee creativity: Evidence from Egyptian organizations. Journal of Business Research, 59: 233-241.

Roffe, I. 1999. Innovation and creativity in organizations: A review of the implications for training and development. Journal of European Industrial Training, 23: 224-241.

Schilling, M. A. 2008. Strategic management of technological innovation. Boston: McGraw-Hill.

Scott, R. K. 1995. Creative employees: A challenge to managers. Journal of Creative Behavior, 29: 6471.

Scott, S. G., \& Bruce, R. A. 1994. Determinants of innovative behavior: A path model of individual innovation in the workplace. Academy of Management Journal, 37: 580-607.

Shalley, C. E., \& Gilson, L. L. 2004. What leaders need to know: A review of social and contextual factors that fosters or hinder creativity. Leadership Quarterly, 15: 33-53.

Shalley, C. E., Zhou, J., \& Oldham, G. R. 2004. The effects of personal and contextual characteristics on creativity: Where should we go from here?. Journal of Management, 30: 933-958.

Smith, G. P. 2002. The new leader: Bringing creativity and innovation to the workplace. Conyers, GA: Chart Your Course. 
Snijders, T. A. M., \& Bosker, R. J. 1999. Multilevel analysis: An introduction to basic and advanced multilevel modeling. London: Sage.

Stam, E., de Jong, J. P. J., \& Marlet, G. 2008. Creative industries in the Netherlands structure, development, innovativeness and effects on urban growth. Geografiska Annaler: Series B, Human Geography, 90: 119-132.

Su, Y.-S., Tsang, E. W. K., \& Peng, M. W. 2009. How do internal capabilities and external partnerships affect innovativeness?. Asia Pacific Journal of Management, 26(2): 309-331.

Teigland, R., \& Wasko, M. M. 2003. Integration knowledge through information trading: Examining the relationship between boundary spanning communication and individual performance. Decision Sciences, 34: 261-287.

Tesluk, P. E., Farr, J. L., \& Klein, S. R. 1997. Influences of organizational culture and climate on individual creativity. Journal of Creative Behavior, 31: 27-41.

Thai Tambon. 2009. http://www.thaitambon.com/English/index.htm, Accessed Apr. 9, 2010.

Thai Tambon. 2010. http://www.thaitambon.com/English/index.htm, Accessed Apr. 9, 2010.

Thanathikom, W. 2005. Creative entrepreneurship in Asia. Country paper (Thailand 1), Asian Productivity Organization, Tokyo, Japan.

Tjosvold, D., \& Yu, Z. 2007. Group risk taking: The constructive role of controversy in China. Group \& Organization Management, 32: 653-674.

Tongboonrawd, B., \& Sukpradit, S. 2007. The rural entrepreneurship and government assistance: Evidences from OTOP [One Tambon (Village), One Product] cases in Thailand. Unpublished Master's thesis, Mälardalen University, Västerås, Sweden.

Tse, H. H. M., Dasborough, M. T., \& Ashkanasy, N. M. 2008. A multi-level analysis of team climate and interpersonal exchange relationships at work. Leadership Quarterly, 19: 195-211.

Vermeulen, P. A. M., O’Shaughnessy, K. C., \& de Jong, J. P. J. 2003. Innovation in SMEs: An empirical investigation of the input-throughput-output-performance model. EIM SCALES paper no. N200302, EIM, Zoetermeer, the Netherlands.

Wech, B. A., \& Heck, A. L. 2004. An introduction to hierarchical linear modeling for marketing researchers. Marketing Bulletin, 15: 1-8.

West, M. A. 1990. The social psychology of innovation in groups. In M. A. West \& J. L. Farr (Eds.). Innovation and creativity at work: Psychological and organizational strategies: 309-333. Chichester, UK: Wiley.

Williams, R. L., Verble, J. S., Price, D. E., \& Layne, B. H. 1995. Relationship of self-management to personality type and indices. Journal of Personality Assessment, 64: 494-506.

Wongtada, N., \& Rice, G. 2008. Multidimensional latent traits of perceived organizational innovation: Differences between Thai and Egyptian employees. Asia Pacific Journal of Management, 25(3): 537-562.

Woodman, R. W., Sawyer, J. E., \& Griffin, R. W. 1993. Toward a theory of organizational creativity. Academy of Management Review, 18: 293-321.

Youngsuksathaporn, P. 2005. Innovation in Thai government. In S. L. Emery, W. Ellis \& M. Chulavatnatol (Eds.). Thailand competitive innovation strategies: 113-150. Bangkok: National Innovation Agency.

Yuan, F. 2005. Individual innovation in the workplace: The role of performance and image outcome expectations. Unpublished doctoral dissertation, Texas A\&M University, College Station, Texas.

Karun Pratoom ( $\mathrm{PhD}$, Srinakarinwirot University) is currently an assistant professor of management at the Mahasarakham University. He is also an Associate Dean for Graduate Study and Research of Faculty of Accountancy and Management, Mahasarakham University, Thailand. His research interests are strategic management and human resource management with a focus on the Asia Pacific.

Gamon Savatsomboon (DBA, University of South Australia) is a faculty member at Faculty of Accountancy and Management, Mahasarakham University (MSU), Thailand. He is also a manager of MSU Book Center supervising over 80 employees. His research interests are in international business and management, electronic government, and higher education with a focus on the Asia Pacific. 